\title{
A different perspective on science
}

\author{
A recent survey revealed striking differences between the public and scientists' views of US scientific achievement \\ and its societal benefits. This reinforces the fact that more must be done to effectively communicate with, educate \\ and engage the public.
}

$\mathbf{T}$ his July marked the 40th anniversary of the Apollo 11 space mission, which documented in spectacular fashion man's first walk on the moon. This historic event solidified the United States' dominance in the space race and showed the strength of the NASA science program in the midst of the Cold War.

This first mission to the moon was once thought to be a giant leap for the United States (and, of course, for mankind), but now that accomplishment seems like a distant memory and perhaps no longer such a great feat. In fact, a recent survey found that only slightly more than a quarter of those polled felt that the United States' greatest achievement during the past 50 years was somewhere in the realm of science, medicine and technology, with only $12 \%$ thinking that space exploration was the nation's greatest achievement. Just 10 years ago, when asked about the United States' greatest achievement during the 20 th century, $47 \%$ of those surveyed felt it was in the area of science, medicine and technology, with $18 \%$ citing specifically space exploration and getting a man on the moon. Perhaps even more sobering are the numbers of those who responded "Nothing" or that they don't know what the nation's greatest achievement is, up from $24 \%$ to $33 \%$.

The new survey, conducted by the Pew Research Center for the People \& the Press (http://people-press.org) and the American Association for the Advancement of Science, involved $\sim 2,000$ people from the general public and $\sim 2,500$ scientists, including teachers, researchers and administrators. The survey, aimed to get some clues into how we think about science and its impact on society, was unique in that, while gauging the general public's opinion and understanding of science, it also asked both groups about hot topic issues and to provide an assessment of how science in the United States is faring.

The survey reveals clear disparities between the public's perception of US-based science research and that of scientists. For example, whereas many of the survey's participants (84\%) acknowledged the importance of scientific contributions to society, ranking scientists third only behind military personnel and teachers in their contribution to society's well-being, only $17 \%$ felt that US scientific achievements placed us as the best in the world in this regard (although $47 \%$ did rank it as "above average"). This is in striking contrast to US scientists' assessment-94\% of the scientists surveyed think that our scientific achievements place us as the best or better than average compared to other industrialized nations. However, nearly three-quarters of the surveyed public acknowledged that federal funding of basic science research, including engineering and technology, would yield long-term benefits to society.
Why is there this apparent disconnect between the public view of science's contributions and how scientists perceive the quality and importance of research performed in the United States? One major factor, at least according to scientists, is education. Of the scientists surveyed, $85 \%$ viewed the lack of understanding of science by the general public as a major problem. Indeed, the general public received a barely passing grade on a short 12-question quiz (http://pewresearch.org/sciencequiz/) of basic textbook science ("True or False: Electrons are smaller than atoms") and more current science topics ("The global positioning system, or GPS, relies on which of these to work? Satellites, Stars, Magnets or Lasers"). Another factor is science communication. Television and newspaper coverage of science did not rate well among scientists, a major issue cited being the lack of distinction between well- and poorly founded studies.

Even more telling is the difference in perception on hot topic issues such as climate change and evolution. Whereas $97 \%$ of the scientists surveyed believe that humans and living things evolve over time, $61 \%$ of the public agreed, but roughly a third of these people felt that this was guided by a supreme being. In addition, more than a quarter of those surveyed believed that there is lack of scientific consensus on this issue. Although a large majority of the public feels that climate change is indeed occurring, only half feel that this is due to human activity, as opposed to $84 \%$ of scientists surveyed. A third of the general public feels that there is lack of scientific consensus on this issue, and less than half feel that it is a very serious problem.

Perhaps unsurprisingly, the public's perception of scientific consensus on these two issues paralleled their own personal views and beliefs. And this may give us some insights into how best to reach and educate the public on scientific issues. Although improving the quality of education as a means to better engage the public is one obvious and important aspect to consider, the survey clearly reveals that the general public applies its own beliefs when absorbing and filtering scientific information. As scientists, rather than speaking down or lecturing to the general public (or even worse, throwing our hands up in despair), we may be better off showing them a bit more of the respect they have for us and trying to see things from their perspective. Another worthwhile approach would be for scientists to present a more unified front, stating more definitively that there is a general scientific consensus on important issues so that a questioning public would not make incorrect assumptions about what has and has not already been scientifically established. 